\title{
LEVANTAMENTO DO IMPACTO DAS RODOVIAS BR-376, BR-373 E BR-277, TRECHO DE APUCARANA A CURITIBA, PARANÁ, NO ATROPELAMENTO DE ANIMAIS SILVESTRES
}

\section{A STUDY OF THE IMPACT OF FEDERAL ROADS BR-376, BR-373 AND BR- 277 ROADS, APUCARANA AND CURITIBA, PARANÁ STRETCH ON THE RUN OVER OF WILD ANIMALS}

\author{
Leticia Polesel Weiss' ${ }^{1}$; Verônica Oliveira Vianna² \\ ${ }^{1}$ Bacharelado em Ciências Biológicas, Universidade Estadual de Ponta Grossa, PR, Brasil. \\ E-mail: <leticia_w@hotmail.com> \\ ${ }^{2}$ Professora Adjunta do Departamento de Zootecnia, Universidade Estadual de Ponta Grossa, \\ PR, Brasil. E-mail: <jrvero@uol.com.br>
}

Data de recebimento: 02/11/2012

Data da aprovação: 10/12/2012

\section{RESUMO}

Atualmente, a produção de carros e a quilometragem das estradas estão crescendo cada vez mais. Esse desenvolvimento traz alguns pontos positivos para a sociedade, principalmente o desenvolvimento econômico. Porém, deve-se ressaltar que elas também podem trazer impactos negativos para a fauna local. O presente trabalho teve como objetivo avaliar a influência das Rodovias BR-376, BR-373 e BR-277, trecho entre Apucarana e Curitiba, totalizando 366 quilômetros, sobre a fauna silvestre da região. Foram quantificados 3.831 atropelamentos entre janeiro de 2007 e dezembro de 2010, o que contabilizou, em média, 10 atropelamentos por quilômetro durante o período avaliado. A classe que teve maior índice de animais mortos foi a dos mamíferos $(\mathrm{n}=3.507)$, principalmente a ordem dos carnívoros $(\mathrm{n}=1.165)$. Os animais mais afetados foram a raposa $(n=921)$, o tatu $(n=832)$ e o gambá $(n=603)$. A estação do ano que apresentou maior número de atropelamentos foi a primavera, devido à maior disponibilidade de alimentos e maior deslocamento dos animais, além de ser o período de reprodução de muitas espécies. Com relação aos trechos mais críticos das rodovias, foram levantados cinco trechos com mais de 150 atropelamentos. Desta forma, concluise que o trecho total estudado influencia na fauna silvestre da região, sendo necessária a implantação de medidas mitigadoras para minimizar este impacto.

Palavras-chave: Animais mortos. Espécies ameaçadas. Estradas.

\begin{abstract}
The production of cars and construction of the roads is increasingly growing; this development brings a number of positive factors to society, in particular economic development. Nevertheless, this can have a negative impact on the local fauna. This study aimed to evaluate the influence on the wildlife nearby the federal roads BR376, BR-373 and BR-277, in particular the stretch between Apucarana and Curitiba, a total of $366 \mathrm{~km}$. The study shows that 3831 road kills took place from January 2007 to December 2010, which accounted for an average of 10 road kills per mile during the period studied. The class of animals that had the highest rate of deaths were the
\end{abstract}


mammals $(n=3507)$, specially carnivores $(n=1165)$. The most affected animals were foxes ( $\mathrm{n}=921)$, armadillos ( $\mathrm{n}=832)$, and opossums $(\mathrm{n}=603)$. The season with the highest number of accidents was spring due to greater availability of food and more movement of animals, and also because it is the period of reproduction of many species. With respect to the most critical stretches of the road, 5 stretches were identified with more than 150 road kills. Thus, it was concluded that road stretches influence the wildlife of the region; therefore, it is relevant to use mitigation measures to minimize this impact.

Keywords: Dead animals. Endangered species. Roads.

\section{Introdução}

A maior parte da história do desenvolvimento econômico do Brasil está associada à construção de estradas e à produção de veículos automotores. Talvez seja por esta razão que, no imaginário brasileiro, elas estão muito associadas às ideias de progresso e modernidade (PRADA, 2004). Além disso, as estradas são empreendimentos necessários ao desenvolvimento da vida humana (SCOSS, 2002).

Elas são estruturas complexas que servem como via de transporte terrestre, possibilitando a movimentação de pessoas e de produtos entre cidades, estados e até países. Por elas são transportadas as safras agrícolas e os insumos necessários para produzi-las, produtos industriais, quase toda a produção intelectual humana impressa como jornais e revistas, máquinas, combustíveis, produtos minerais e qualquer outro material que a humanidade utilize (BANDEIRA; FLORIANO, 2004).

Mas apesar de todo o desenvolvimento que as estradas proporcionam ao homem, como incentivar a ocupação humana ou promover o desenvolvimento econômico, elas também causam diversos danos à natureza. Esses danos afetam o homem, direta ou indiretamente, alterando a qualidade de vida no âmbito regional, nacional e até mundial. A introdução de estradas cruzando áreas naturais é um dos primeiros passos para o início do processo de alteração de ambientes (FISHER, 1997). Elas representam um dos maiores males da civilização quanto aos impactos sobre o ambiente natural (BANDEIRA; FLORIANO, 2004).

A fragmentação de hábitats causada por ação antrópica vem sendo um dos grandes desafios para a biologia da conservação e é uma das principais ameaças à biodiversidade (ZAÚ; FREITAS, 2007). As estradas, durante o processo de construção, infligem principalmente a alteração direta do hábitat, produzindo um ambiente físico e químico diferente daquele dasáreas adjacentes (FREITAS, 2009), através da remoção da cobertura vegetal original, podendo gerar efeito de borda e alterar a função e a estrutura da paisagem, em contraste com a necessidade e o alto valor econômico imposto pela sociedade humana (PRADO; FERREIRA; GUIMARÃES, 2006).

Além de alterar a paisagem, este tipo de empreendimento facilita o acesso humano a áreas até então remotas, promovendo desmatamento, extração de madeira, caça e sendo atrativo para assentamentos humanos, além de outras atividades danosas que causam impactos localizados, como a mortalidade de animais silvestres por atropelamento (SILVA; VIANNA, 2009) e a queda populacional de espécies de aves e outros animais devido aos ruídos provocados pelos veículos que transitam pelas estradas (CIOCHETI; ABRA, 2009). Estas modificações acarretam sérios impactos à fauna de vertebrados que precisa se deslocar e atravessar as rodovias, e acabam funcionando como uma barreira artificial e elevando o índice de mortalidade (PENÃ; DRUMOND, 1999; DIAS et al., 2004 apud PRADO; FERREIRA; GUIMARÃES, 2006).

Os atropelamentos tornam-se um fator de grande impacto sobre a vida silvestre, podendo ser uma das principais causas de mortalidade, inclusive para espécies ameaçadas de extinção, sendo considerada a fonte primária de morte em estradas (CHEREM et al., 2007). Por isso é importante que se tenha uma noção dos prejuízos causados sobre a fauna local (NOVELLI; TAKASE; CASTRO, 1988). 
Quando os atropelamentos ocorrem próximos e no entorno de Unidades de Conservação (UCs), o problema se torna ainda maior, já que estas áreas constituem refúgios naturais para a fauna (GUIMERCOSTA; SPERBER, 2009) e muitas delas abrigam espécimes ameaçadas de extinção (LIMA; OBARA, 2004). Esta constatação demonstra que unidades de conservação, como áreas de proteção permanente, parques e reservas, entre outros, são incompatíveis com este tipo de empreendimento (PRADO; FERREIRA; GUIMARÃES, 2006).

Segundo Lima e Obara (2004), os atropelamentos podem ocorrer por dois motivos principais: (1) porque a rodovia corta o hábitat de determinadas espécies, interferindo assim na faixa do seu deslocamento natural ; e (2) porque, ao longo da rodovia, existe uma grande quantidade de alimentos (grãos, sementes, frutas, plantas herbáceas e outros) disponíveis, sendo um atrativo para a fauna. Neste caso, pode ser criado um ciclo de atropelamento (figura 1), em que os animais são inicialmente atraídos pelo alimento presente no outro lado da rodovia e, no momento da travessia, são atropelados e tornam-se atrativos para animais carnívoros, podendo causar o atropelamento destes também.

Figura 1 - Ciclo de atropelamentos da fauna silvestre.

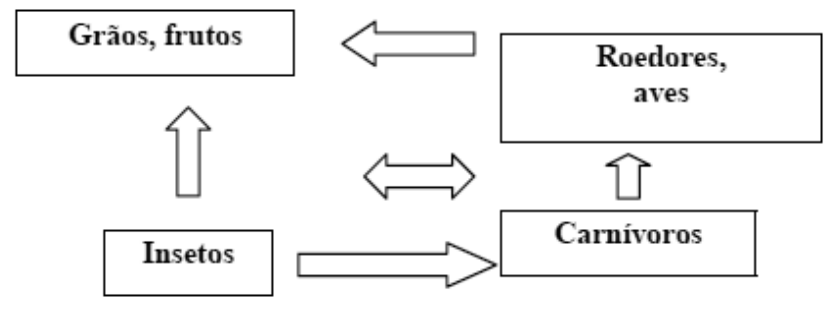

Fonte: DNER/IME, (2001) apud LIMA; OBARA, (2004)

A gama de espécies atropeladas é enorme, envolvendo tanto invertebrados como vertebrados. Entre os vertebrados, objeto deste estudo, os afetados compreendem quatro classes de animais: anfíbios, répteis, aves e mamíferos, que apresentam hábitos de vida variados (noturnos, diurnos, terrestres, arborícolas, entre ouros) e, para algumas espécies, as taxas de atropelamento podem ser significativas (CHEREM et al., 2007). Porém os acidentes que envolvem animais de grande porte ganham maior importância na sociedade devido à possibilidade de causarem danos aos veículos e fatalidades aos seres humanos (BAGATINI, 2006).

No Brasil, devido ao modelo que prioriza o transporte rodoviário, os atropelamentos em rodovias são extremamente importantes (BAGATINI, 2006) e, a cada ano, o número de animais mortos em rodovias brasileiras pode ser bastante relevante e agravado principalmente naquelas com grande fluxo de automóveis e que cortam áreas potencialmente ricas em fauna e flora (CASELLA et al., 2006).

Mesmo tendo as rodovias uma forte influência no número de mortes de animais por atropelamentos, uma grande parte dos acidentes é ocasionada por fatores externos, como a imprudência de motoristas que não respeitam as sinalizações de tráfego e a deposição de lixo ao longo da rodovia (SILVA; VIANNA, 2009).

É importante ressaltar que as taxas de atropelamento em geral são subestimadas. Os animais que não morrem no momento da colisão deslocam-se para a vegetação adjacente, morrendo posteriormente e não sendo, assim, contabilizados (FISHER, 1997).

O presente trabalho teve como objetivo levantar os atropelamentos que ocorreram ao longo da Rodovia BR-376, no trecho Apucarana - Ponta Grossa e Ponta Grossa - São Luiz do Purunã, BR-373, no trecho que compreende a área urbana de Ponta Grossa, e da Rodovia BR-277, no trecho São Luiz do Purunã - Curitiba, para verificar se eles estão interferindo significativamente na fauna local.

\section{Material e métodos}

- Área de estudo

A área de estudo compreendeu a BR-376, BR373 e BR-277 (figura 2). Na BR 376, o trabalho teve início na cidade de Apucarana, passando pelas cidades de Califórnia, Matelândia do Sul, Mauá da Serra, Ortigueira, Imbaú, Ponta Grossa e terminando em São Luiz do Purunã, compreendendo um trecho de $309 \mathrm{~km}$ de extensão. A cidade de Apucarana, na região centro norte do estado e o distrito de São Luiz do Purunã, pertencente ao município de Balsa Nova, na região metropolitana de Curitiba são, respectivamente, início e término da administração da Concessionária Rodonorte (CCR Rodonorte) nesta rodovia. $\mathrm{Na}$ BR-373, o trecho compreendido foi na região urbana de Ponta Grossa, com $11 \mathrm{~km}$ de extensão. E na BR 
- 277, o trecho estudado foi entre São Luiz do Purunã e Curitiba, também sob administração da CCR
Rodonorte e com $46 \mathrm{~km}$ de extensão. Sendo assim, a extensão total da área de estudo foi de $366 \mathrm{~km}$.

Figura 2 - Mapa referente à área de abrangência da CCR Rodonorte. Em vermelho, o trecho da BR-277, em azul os trechos da BR-376 e em laranja o trecho da BR-373 (Fonte: CCR Rodonorte).

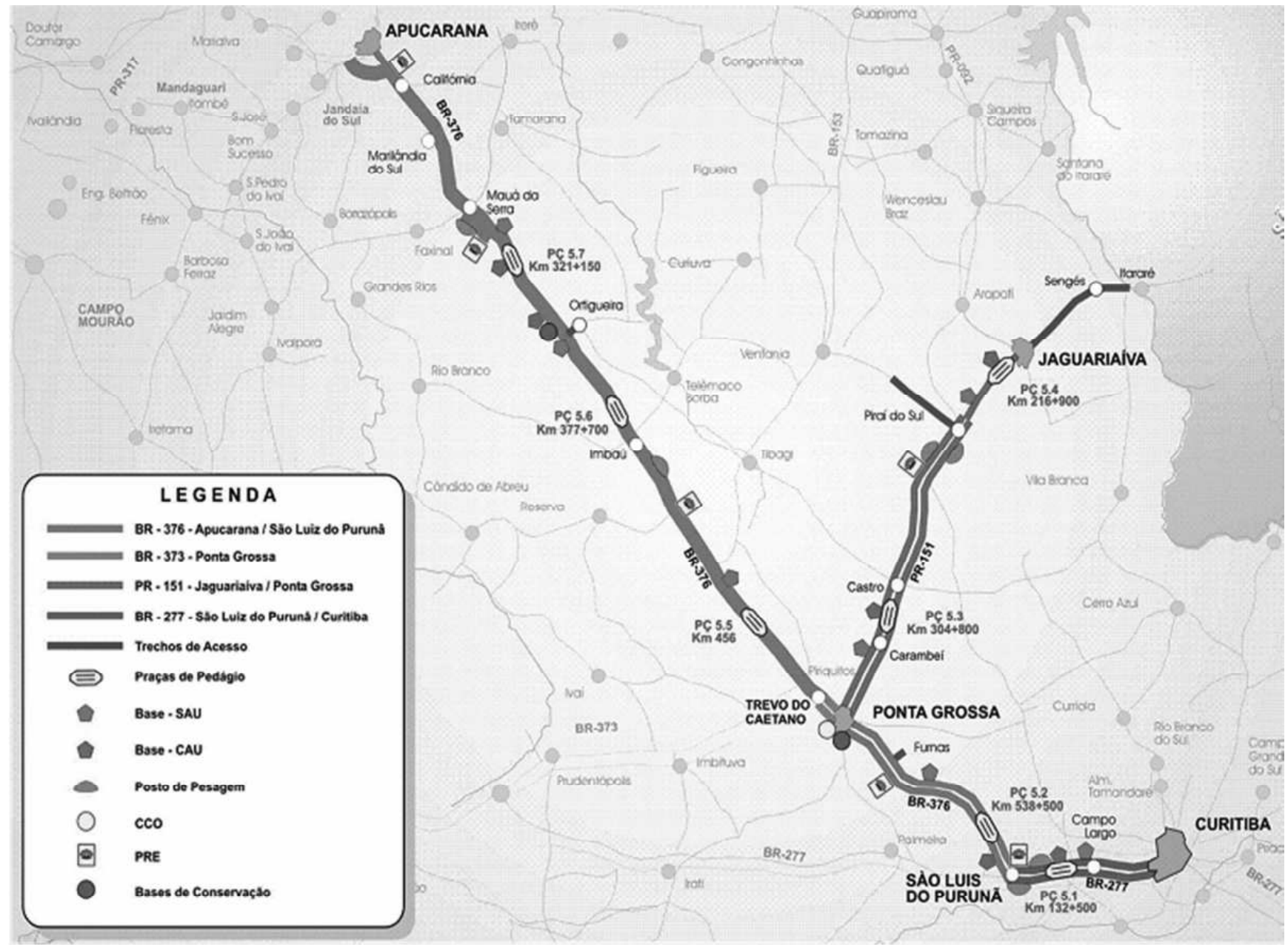

A BR - 376, também conhecida como Rodovia do Café, tem grande importância no Paraná, pois é um corredor viário que corta todo o estado, ligando o norte e noroeste à capital e ao estado de Santa Catarina (SILVA; VIANNA, 2009). A BR - 277 atravessa o estado no sentido leste-oeste, com início na cidade de Paranaguá e término em Foz do Iguaçu, onde se liga à Rodovia Transparaguaiana.

Juntas, estas rodovias são consideradas importantes vias de escoamento da safra brasileira, apresentando grande fluxo de veículos, principalmente de caminhões, que seguem destino ao Porto de Paranaguá, no litoral do Paraná, ou para o Mato Grosso do Sul, em sentido noroeste do estado.

\section{- Metodologia}

Para o desenvolvimento do presente trabalho contou-se com o Setor de Concessão de Rodovias do Departamento de Estradas de Rodagem (DER), Superintendência dos Campos Gerais. Junto com o DER, foi realizado um levantamento dos boletins feitos pelas concessionárias sobre as estradas de sua administração. Esses boletins relatam diversos aspectos sobre o meio ambiente nas rodovias como, por exemplo, os atropelamentos de animais silvestres. Estes dados são coletados a cada hora, pois carros de apoio da concessionária passam pelo mesmo trecho a cada hora. É importante ressaltar que a equipe que faz este monitoramente não é preparada para identificar os animais 
cientificamente, sendo relatados apenas com seus nomes populares. Desta forma, muitas espécies podem ser confundidas, como é o caso da raposa, do cachorro do mato e do graxaim.

A partir desses dados, foram analisados os seguintes fatores: as espécies de animais mais atropeladas na rodovia no trecho entre Apucarana e Curitiba; a estação do ano que mais ocorreram estes acidentes; e qual o trecho de maior ocorrência dos atropelamentos (SILVA; VIANNA, 2009). Para analisar a estação do ano de maior incidência, foi verificada a data de cada atropelamento, contabilizando o total por estação. Para analisar o trecho mais crítico, a extensão total foi divida em 37 trechos: 36 trechos com dez quilômetros de extensão cada e um com seis quilômetros. O período analisado teve início em janeiro de 2007 e término em dezembro de 2010, totalizando quatro anos de trabalho.

Com estas informações pôde-se avaliar a conservação local e sugerir áreas prioritárias para proteção e manejo da fauna que utiliza as rodovias como parte do seu hábitat (FISCHER, 1997).

\section{- Análise estatística}

Para análise dos dados, foi utilizado o teste estatístico não paramétrico ANOVA - um critério $(\mathrm{p}=0,05)$. Para avaliar se a variação foi significativa durante as estações do ano e entre as classes de animais, aplicou-se o teste de Tukey $(\mathrm{p}=0,01)$. Ambos os testes foram aplicados utilizando o programa BioEstat 5.0.

\section{Resultados e discussões}

- Animais atropelados

Durante o período analisado, a equipe da Concessionária CCR Rodonorte registrou 3.831 atropelamentos de vertebrados silvestres em 366 quilômetros de rodovia, gerando a média de 10 atropelamentos por quilômetro durante os 4 anos. Esse número pode ser subestimado, já que algumas vezes os animais não morrem imediatamente no momento da colisão, mas podem se retirar da pista e adentrar na vegetação adjacente, agonizando tempo depois do impacto, não sendo encontrados e contabilizados. Fischer (1997) ressalta que pequenos vertebrados mortos podem ser facilmente carregados por animais necrófagos, não sendo contabilizados também.
A variação desses atropelamentos durante os anos pode ser observada nos gráficos 1 e 2 . No ano de 2007, o número de atropelamentos foi de 766 (20\%); em 2008 foram 989 (26\%) atropelamentos; em 2009, foram 1134 (29\%), sendo o ano em que mais ocorreram acidentes; e, em 2010, 942 (25\%) atropelamentos. De acordo com o teste estatístico ANOVA $(p=0,05)$, a variação entre o número de atropelamentos por ano não foi significativa.

Gráfico 1 - Número de atropelamentos por ano no trecho da Rodovia entre Apucarana e Curitiba, compreendendo a BR-376, BR-373 e BR-277.

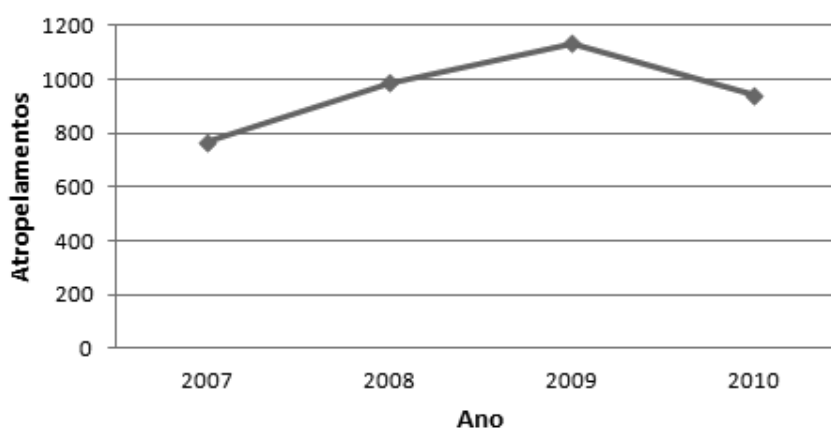

Gráfico 2 - Porcentagem de atropelamentos ocorridos em cada ano no trecho da Rodovia entre Apucarana e Curitiba, compreendendo a BR-376, BR373 e BR-277.

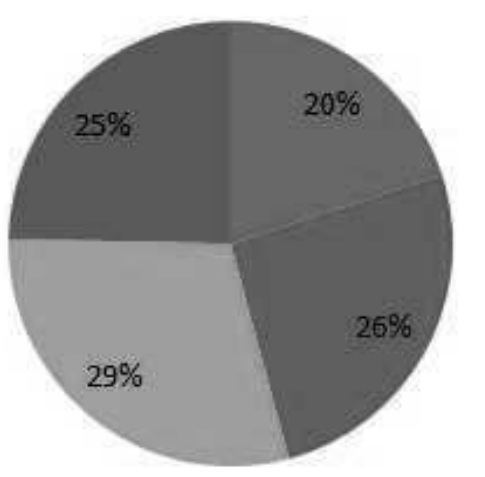

2007 2008 2009

2010

Esses atropelamentos são distribuídos nas classes de acordo com o gráfico 3. Os mamíferos foram os mais atropelados, apresentando um número total de 3.507 (92\%); em seguida, os répteis com 196 atropelamentos, o que representa $5 \%$ do total; 125 aves (3\%) foram atropeladas; na classe dos anfíbios houve apenas 1 atropelamento registrado e 2 animais não foram identificados, valores que não chegam a representar $1 \%$ do total. 
Gráfico 3 - Representa a porcentagem das classes de animais atropelados, mamíferos, aves, répteis e anfíbios, nos $366 \mathrm{~km}$ estudados, entre as cidades de Apucarana e Curitiba.

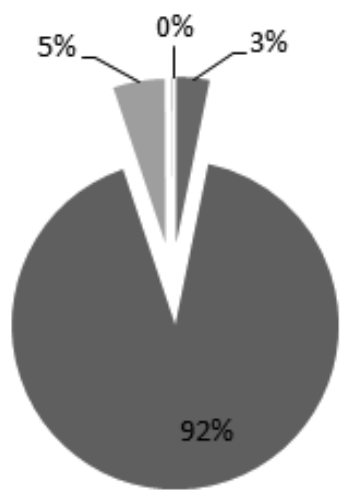

aves

- Mamíferos

Répteis

Anfíbios e animais não identificados

O teste Tukey $(\mathrm{p}=0,01)$ mostrou que a diferença entre as classes foi significativa. Essas diferenças são notadas quando a comparação é feita entre a classe dos mamíferos e as demais. Comprando-se as outras classes não houve diferença significativa (tabela 1).

Tabela 1 - Comparação das medias de atropelamentos entre as classes de animais nos trechos da BR-376 entre Apucarana e São Luiz do Purunã, BR373 no trecho de Ponta Grossa e BR-277 entre São Luiz do Purunã a Curitiba.

\begin{tabular}{c|c}
\hline Classe & Médias \\
\hline Mamíferos & $877 \quad$ a \\
\hline Répteis & $49,25 \mathrm{~b}$ \\
\hline Aves & $31,25 \mathrm{~b}$ \\
\hline Anfíbios & $0,25 \quad \mathrm{~b}$ \\
\hline
\end{tabular}

Letras distintas na mesma coluna diferem entre si pelo teste de Tukey $(\mathrm{p}=0,01)$.
Os resultados encontrados neste trabalho, no que diz respeito à classe dos mamíferos, foram extremamente altos (tabela 2) quando comparados com outros trabalhos, como o de Lima e Obara (2005), que registraram 165 atropelamentos em $32 \mathrm{~km}$ da BR 277 e $45 \%$ do total foi de mamíferos. Melo e Santos-Filho (2007) analisaram $63 \mathrm{~km}$ da BR-070, no Mato Grosso do Sul, de novembro de 2000 até outubro de 2001 e registraram 211 atropelamentos, dos quais $59 \%$ foram de mamíferos.

Meneguetti, Meneguetti e Trevisan (2010) também constataram que os mamíferos foram os mais afetados, tendo $50 \%$ dos animais encontrados mortos pertencentes a esta classe em $36 \mathrm{~km}$ de rodovia na linha 200 entre os municípios Ouro Preto do Oeste e Vale do Paraíso (RO). Silva, Barbosa e Godoy (2011) registraram 113 atropelamentos em um trecho de 47 $\mathrm{km}$ na BR 153, entre setembro de 2005 e junho de 2006, exceto o mês de maio, sendo $45 \%$ do total de mamíferos.

Já se compararmos com Moreira et al. (2006), os valores são aproximados. Os autores registraram 264 mamíferos mortos por atropelamentos num total de 307 animais na Rodovia GO-060 num trecho de $216 \mathrm{~km}$, representando $86 \%$ do total.

Como afirmam Silva, Barbosa e Godoy (2011), os mamíferos podem ser tornar mais territorialistas com as perturbações causadas pela fragmentação do ambiente em função da construção de rodovias. Além disso, estes animais precisam se deslocar entre os fragmentos gerados, aumentando, assim, o risco de acidentes. Em razão de este grupo ser altamente dependente de seus padrões espaciais, ocorre um grande número de atropelamentos (MATHIAS et al. 2004 apud SILVA, BARBOSA; GODOY, 2011).

Tabela 2 - Espécies de mamíferos atropeladas e encontradas mortas na rodovia, no trecho entre Apucarana e Curitiba, durante os anos de 2007, 2008, 2009 e 2010, bem como suas quantidades.

\begin{tabular}{c|c|c}
\hline Taxa & Nome popular & \\
\hline Mammalia & & \\
\hline Ordem Artiodactyla & veado & juantidade \\
\hline Família Cervidae & porco do mato & \\
\hline Família Suidae & 1 & \\
\hline Família Tayassuidae & cachorro do mato & \\
\hline Ordem Carnívora & graxaim & \\
\hline Família Canidae & lobo guará (Chrysocyon brachyurus) & \\
\hline & raposa (Pseudalopex sp.) & 23 \\
\hline
\end{tabular}


conclusão

\begin{tabular}{|c|c|c|}
\hline Taxa & Nome popular & Quantidade \\
\hline \multirow[t]{3}{*}{ Família Felidae } & gato do mato (Leopardus tigrinus) ${ }^{*}$ & 16 \\
\hline & jaguatirica (Leopardus pardalis) ${ }^{*}$ & 21 \\
\hline & suçuarana $(\text { Puma concolor })^{*}$ & 1 \\
\hline \multirow[t]{3}{*}{ Família Mustelidae } & furão (Mustela sp.) & 2 \\
\hline & irara (Eira barbara) & 1 \\
\hline & lontra (Lontra longicaudis) ${ }^{*}$ & 9 \\
\hline Família Procyonidae & quati (Nasua nasua) & 57 \\
\hline Família Maphitidae & zorrilho (Conepatus chinga) & 1 \\
\hline \multicolumn{3}{|l|}{ Ordem Cingulata } \\
\hline Família Dasypodidae & tatu & 832 \\
\hline \multicolumn{3}{|l|}{ Ordem Didelphimorphia } \\
\hline Família Didelphidae & gambá (Didelphis sp.) & 603 \\
\hline \multicolumn{3}{|l|}{ Ordem Erinaceomorpha } \\
\hline Família Erinaceidae & ouriço & 266 \\
\hline \multicolumn{3}{|l|}{ Ordem Lagomorpha } \\
\hline Família Leporidae & lebre & 425 \\
\hline \multicolumn{3}{|l|}{ Ordem Pilosa } \\
\hline Família Myrmecophagidae & tamanduá & 39 \\
\hline \multicolumn{3}{|l|}{ Ordem Primates } \\
\hline & macaco & 4 \\
\hline & sagui & 1 \\
\hline Família Atelidae & bugio (Alouatta guariba) $)^{*}$ & 3 \\
\hline \multicolumn{3}{|l|}{ Ordem Rodentia } \\
\hline \multirow[t]{2}{*}{ Família Caviidae } & capivara (Hydrochoerus hydrochaeris) & 82 \\
\hline & preá (Cavia aperea) & 4 \\
\hline Família Cuniculidae & paca $\left(\right.$ Cuniculus paca) ${ }^{* *}$ & 3 \\
\hline Família Dasiproctidae & cutia (Dasyprocta aguti) & 3 \\
\hline Família Erethizontidae & porco espinho (Hystrix cristata) & 9 \\
\hline
\end{tabular}

* Animais considerados Vulneráveis (VU) segundo o Livro Vermelho da Fauna Ameaçada no Estado do Paraná (2004).

** Animais considerados Em Perigo (EN) segundo o Livro Vermelho da Fauna Ameaçada no Estado do Paraná (2004).

Das 28 espécies de mamíferos afetadas, cinco delas (Leopardus tigrinus, Leopardus pardalis, Puma concolor, Lontra longicaudis, Alouatta guariba) constam na categoria "Vulnerável", e duas (Chrysocyon brachyurus e Cuniculus paca) constam na categoria "Em perigo" de acordo com o Livro Vermelho da Fauna Ameaçada no Estado do Paraná (2004).

Nos boletins foram registrados 39 atropelamentos de tamanduá. Como a equipe responsável pelos boletins não determina qual a espécie de tamanduá foi encontrada, estes podem ser tanto o tamanduá mirim (Tamandua tetradactyla) quanto o tamanduá bandeira (Myrmecophaga tridactyla). O último consta no Livro Vermelho da Fauna Ameaçada no Estado do Paraná (2004) na categoria "Criticamente em perigo". Além do tamanduá bandeira, outra confusão que pode ocorrer é com relação a queixada (Tayassu pecari) que pode ser confundida com o cateto (Tayassu tajacu). A queixada (Tayassu pecari) encontra-se na categoria "Criticamente ameaçado" e o cateto, na categoria "Vulnerável". Estes dados refletem a influência que estas rodovias e o fluxo de carro que trafega por elas têm sobre os ecossistemas locais, sendo necessária a implantação de algumas medidas mitigadoras a fim de diminuir a quantidade desses atropelamentos.

Dentro da classe dos mamíferos, das nove ordens atingidas, a Ordem Carnívora foi a mais afeta$\mathrm{da}$, apresentando 33\% (1.165 acidentes) do total de atropelamentos desta classe. Estes dados corroboram com os encontrados por Hengemühle e Cademartori (2008) e Melo e Santos-Filho (2007) que também registraram a Ordem Carnívora entre as mais atingidas.

Segundo Prada (2004), o fato de a Ordem Carnívora ser a mais afetada pode ser explicado em função de estes animais terem grande área de vida, se deslocando por trechos extensos das rodovias e necessitando transpassá-las constantemente em busca principalmente de alimentos e habitat, além de serem animais necrófagos, andando sempre em busca de animais mortos ou carcaças para se alimentarem.

$\mathrm{O}$ animal mais atropelado foi a raposa (Pseudalopex sp.), com 921 atropelamentos no total. 
Em seguida, o tatu com 832, o gambá 603 e a lebre com 425 atropelamentos. As raposas são espécies predadoras e carniceiras, percorrendo grandes trechos nas rodovias em busca de alimentos, tanto presas vivas quanto animais mortos, tornando-as grandes vítimas das rodovias (GUIMER-COSTA; SPERBER, 2009). Como ressaltam Silva e Vianna (2009), o fato de muitos indivíduos da família Dasypodidae (tatus) serem vítimas dos atropelamentos pode ser explicado em função da visão pouco desenvolvida deste grupo aliado aos seus hábitos crepusculares e noturnos.
Dentre as aves (tabela 3), as espécies mais atropeladas foram a coruja, com 77 mortes, e o jacu, com 18. Pela região que o trabalho englobou, pode-se inferir que grande parte dessas corujas pode ser a coruja buraqueira e, devido o seu hábito de vida, esta espécie pode se tornar mais vulnerável aos atropelamentos. Elas apresentam voo baixo, transitando de uma toca para outra, além de possuírem tanto atividades noturnas quanto diurnas (SICK, 1988 apud SILVA; VIANNA, 2009).

Tabela 3 - Espécies de aves atropeladas e mortas na rodovia, no trecho entre Apucarana e Curitiba, durante os anos de 2007, 2008, 2009 e 2010, bem como suas quantidades.

\begin{tabular}{|c|c|c|}
\hline Taxa & Nome popular & Quantidade \\
\hline \multicolumn{3}{|l|}{ Aves } \\
\hline & Não identificados & 6 \\
\hline \multicolumn{3}{|l|}{ Ordem Accipitriformes } \\
\hline Família Cathartidae & urubu & 2 \\
\hline \multicolumn{3}{|l|}{ Ordem Anseriformes } \\
\hline \multirow{2}{*}{ Família Anatidae } & ganso & 1 \\
\hline & pato do mato & 1 \\
\hline \multicolumn{3}{|l|}{ Ordem Charadriiformes } \\
\hline Família Charadriidae & quero-quero (Vanellus chilenses) & 1 \\
\hline \multicolumn{3}{|c|}{ Ordem Ciconiiformes (Falconiformes) } \\
\hline \multirow{3}{*}{ Família Falconidae } & gavião & 9 \\
\hline & falcão & 1 \\
\hline & carcará (Polyborus plancus) & 1 \\
\hline \multicolumn{3}{|l|}{ Ordem Galliformes } \\
\hline Família Cracidae & jacu (Penelope ochrogaster) & 18 \\
\hline Família Phasianidae & faisão & 1 \\
\hline \multicolumn{3}{|l|}{ Ordem Gruiformes } \\
\hline Família Raliidae & saracura (Aramides $s p$.) & 1 \\
\hline \multicolumn{3}{|l|}{ Ordem Piciformes } \\
\hline Família Ramphastidae & tucano & 3 \\
\hline Ordem Strigiforme & coruja & 77 \\
\hline
\end{tabular}

Já na classe dos répteis (tabela 4), os mais afetados foram os lagartos. Estes animais apresentam um agravante que, por serem animais de sangue frio, geralmente procuram pontos quentes no asfalto ou locais onde fiquem expostos ao sol para se aquecerem, tornando-se vítimas fáceis.

Tabela 4 - Espécies de répteis e anfíbios atropelados e mortos na rodovia, no trecho entre Apucarana e Curitiba, durante os anos de 2001, 2008, 2009 e 2010, bem como suas quantidades.

\begin{tabular}{c|c|c}
\hline Taxa & Nome popular & \\
\hline Reptilia & Quantidade & \\
\hline Ordem Crocodilia & jacaré & \\
\hline Família Alligatoridae & lagarto & cobra \\
\hline Ordem Squamata & & 175 \\
\hline Subordem Lacertilia & sapo \\
\hline Subordem Serpentes & & 20 \\
\hline Amphibia & & 2 \\
\hline Ordem Anura & & \\
\hline
\end{tabular}


A pequena quantidade de anfíbios (tabela 4) mortos nas rodovias deve-se ao fato de esses animais serem de pequeno porte, o que faz com que eles sejam rapidamente deteriorados pelo fluxo de carros das rodovias e também por serem facilmente carregados por outros animais que os encontram. Desta forma, muitos deles deixam de fazer parte das estatísticas.

\section{- Sazonalidade}

A sazonalidade também é um fator que pode influenciar no deslocamento das espécies e consequentemente no atropelamento, pois alterações de estações levam a mudanças de comportamento como por exemplo reprodução, busca por alimentos, etc.

A estação do ano em que mais foram registrados os atropelamentos (gráfico 4) foi a primavera, com 1.159 acidentes (30\%); no verão foram registrados1.113 (29\%); outono, 822 (21\%); e, no inverno, $765(20 \%)$.

Gráfico 4 - Porcentagem total dos atropelamentos separados de acordo com a estação do ano que ocorreram no trecho da rodovia entre Apucarana e Curitiba, entre os anos de 2007 a 2010.

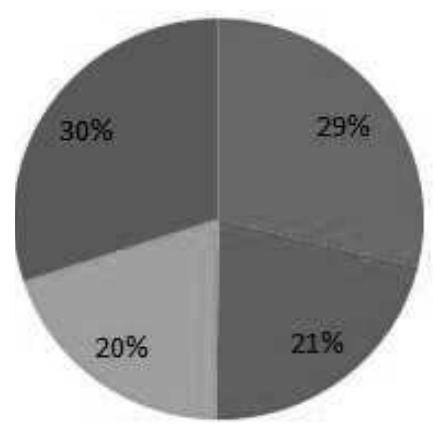

E Verão
E Outono
EInverno
E Primavera

O teste de Tukey $(\mathrm{p}=0,01)$ mostrou que existe variação significativa entre a primavera e o inverno, estações de maior e menor índice de atropelamentos, respectivamente (tabela 5).

Tabela 5 - Comparação do número de atropelamentos que ocorreram nas estações do ano (primavera, verão, outono e inverno), no trecho da rodovia de Apucarana a Curitiba, durante os anos de 2007 a 2010 .

\begin{tabular}{c|c}
\hline Estação do ano & Médias \\
\hline Primavera & $289,75 \mathrm{AA}$ \\
\hline Verão & $278,25 \mathrm{Aa}$ \\
\hline Outono & $205,50 \mathrm{Aa}$ \\
\hline Inverno & $191,25 \mathrm{aa}$ \\
\hline
\end{tabular}

Letras distintas, na mesma coluna, diferem entre si pelo teste de Tukey $(\mathrm{p}=0,01)$ de probabilidade.
Rosa e Mauhs (2004) e Silva e Vianna (2209) também encontraram um maior número de atropelamentos na estação da primavera. $\mathrm{O}$ fato de esta estação apresentar um maior número de acidentes pode ser em decorrência da maior disponibilidade de alimentos e também por ser o período de acasalamento de várias espécies, aumentando a sua locomoção pelas rodovias em busca de parceiros para reprodução ou de alimentos (SILVA; VIANNA, 2009).

\section{- Trechos de maior incidência de atropelamentos}

Para avaliação do estudo, a extensão total do trecho analisado, foi dividida em 36 trechos com dez quilômetros cada e um com seis quilômetros (gráfico 5). Deste total, foram levantados cinco com incidência maior que 150 atropelamentos por trecho, sendo necessário uma análise mais detalhada do seu entorno para supor o motivo do alto índice de acidentes nestas áreas e propor medidas mitigadoras coerentes com a realidade do local. Esta análise foi baseada em mapas contidos nos boletins feitos pela concessionária CCR Rodonorte e fornecidos pelo DER, bem como de imagens do Google Earth 6.1.0.4857 (beta).

Os trechos levantados como críticos foram: trecho quatro, do km 125 ao km 135 da BR-277; trecho seis, do km 541 ao km 551 da BR-376; trecho 23, do $\mathrm{km} 371$ ao $\mathrm{km} 381$ da BR-376; trecho 25, do km 351 ao $\mathrm{km} 361$ da BR-376; e o trecho 33, do $\mathrm{km} 271$ ao km 281 do BR-376.

Gráfico 5 - Distribuição dos atropelamentos por trechos da rodovia, de Apucarana a Curitiba. As colunas em vermelho representam os trechos de maior incidência de atropelamentos.

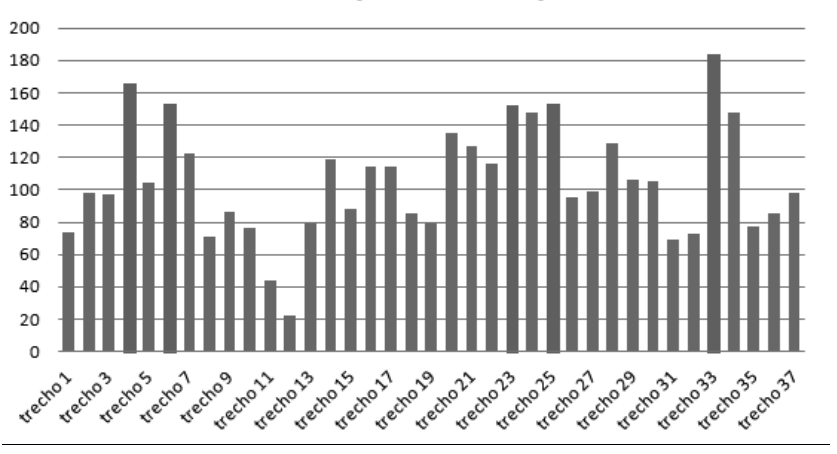


O trecho quatro (do $\mathrm{km} 125$ ao $\mathrm{km} 135$ da BR277) apresentou 166 atropelamentos durante todo o período de trabalho. $\mathrm{O}$ animal mais atropelado nesta extensão foi a raposa. Além disso, neste trecho foram atropelados três espécies que se encontram no Livro Vermelho da Fauna Ameaçada no Estado do Paraná (2004), totalizando seis animais: bugio (2), jaguatirica (1) e a lontra (1). Também foram registrados dois tamanduás. Considerando a região em que os atropelamentos dos tamanduás foram registrados, acredita-se que sejam tamanduás mirins, já que o tamanduá bandeira é encontrado em regiões de cerrado e campos, que caracterizam o Segundo Planalto Paranaense, e raramente avistado em regiões de Floresta Ombrófila Densa.

A análise das imagens dos boletins demonstrou que o trecho compreende uma região de serra com curvas, aclives e declives acentuados e incidência de neblina. Todos esses fatores são responsáveis por aumentar o número de acidentes na região, e a neblina é um fator preocupante, já que diminui a visibilidade dos motoristas, impossibilitando-os de enxergar se existe algum animal cruzando a pista. Além disso, o trecho apresenta uma vegetação exuberante, de grande porte, fornecendo alimentos e abrigo para diversas espécies, determinando a abundância de animais que habitam a região e o consequente índice elevado de atropelamentos.

O trecho seis (do km 541 ao $\mathrm{km} 551$ da BR376) apresentou 153 atropelamentos. O animal mais afetado foi o tatu, além de três espécies ameaçadas de extinção de acordo com o Livro Vermelho da Fauna Ameaçada no Estado do Paraná (2004): lontra (2), jaguatirica (2) e lobo guará (2). Neste trecho também ocorreu o atropelamento de um tamanduá. E da mesma foram que no trecho anterior (trecho quatro), acredita-se que seja um tamanduá mirim devido à área em que foi registrado. Pelas imagens dos boletins, pode-se ver que o trecho engloba o Rio dos Papagaios, possibilitando uma maior quantidade de animais habitando a região, já que todos precisam de água para sua sobrevivência, promovendo um maior fluxo de espécies que transpõe a rodovia em busca de água. Este fato pode explicar os acidentes que vitimaram duas lontras, espécie que habita regiões próximas a lagos ou rios, procurando a maior parte dos seus alimentos nestes locais. Além disso, possui hábitos noturnos e crepusculares, mais um motivo para que ela se torne uma vítima do atropelamento nas estradas. Outro fator agravante é que o trecho compreende uma reta. Neste caso, cabe lembrar que muitas pessoas são imprudentes e aproveitam esses trechos de reta para trafegar ultrapassando o limite de velocidade recomendável para a rodovia, dificultando ainda mais o controle do carro, caso o motorista precisar parar ou desviar de algum animal.

O trecho 23 (do $\mathrm{km} 371$ ao $\mathrm{km} 381$ da BR376) contabilizou 152 mortes de animais silvestres por atropelamentos, sendo o gambá o mais atingido e duas espécies que constam no Livro Vermelho da Fauna Ameaçada de Extinção no Estado do Paraná (2004): jaguatirica (2) e gato do mato (2). Este trecho apresenta características semelhantes ao trecho seis: trecho predominantemente com retas e presença de 3 rios - Rio Caçador, Rio Imbauzinho e Rio Lambedor. Os trabalhos de Bagatini (2006) e Silva e Vianna (2009) corroboram também com os resultados encontrados na presente pesquisa, em que se observam altos índices de atropelamentos em locais próximos a corpos d'água, os quais servem como corredores devido à vegetação ciliar, além de oferecer água e abrigo para os animais.

No trecho 25 (do km 351 ao km 361 da BR376) verificou-se 153 atropelamentos, sendo o gambá o animal mais atingido nesta região e nenhuma espécie em extinção. Esta região apresenta alguns pontos de vegetação exuberante, além de dar acesso a Ortigueira, região de perímetro urbano, o que aumenta o fluxo de veículos no local, interferindo no índice de atropelamento de animais silvestres.

O trecho considerado mais crítico foi o $33(\mathrm{~km}$ 271 ao km 281 do BR-376) com um total de 184 animais atropelados. O tatu foi o animal mais atingido, e outro fator agravante desta área é o atropelamento de 4 espécies de animais que constam no Livro Vermelho da Fauna Ameaçada de Extinção do Paraná (2004): jaguatirica (2), lontra (1), suçuarana (1) e tamanduá (1). A região apresenta certo grau de urbanização, o que aumenta o tráfego local e pode ter influenciado na elevada incidência de acidentes. Além disso, este trecho também é predominante em retas, o que faz com que muitos motoristas aumentem a velocidade.

\section{Conclusões}

O trabalho realizado nas rodovias BR-376, BR-373 e BR-277, no trecho entre as cidades de 
Apucarana e Curitiba, no estado do Paraná, revelou índices preocupantes de atropelamentos de animais silvestres, principalmente de mamíferos, indicando que as referidas rodovias influenciam o cotidiano da fauna local. Observou-se que a classe dos mamíferos foi a mais afetada, com 7 espécies constando no Livro Vermelho da Fauna Ameaçada no Estado do Paraná (2004): cinco delas (Leopardus tigrinus, Leopardus pardalis, Puma concolor, Lontra longicaudis, Alouatta guariba) na categoria de "Vulnerável" e duas (Chrysocyon brachyurus e Cuniculus paca) na categoria "Em perigo". Além disso, existem três espécies que foram afetadas e possivelmente estão na lista: o tamanduá bandeira (Myrmecophaga tridactyla) e o queixada (Tayassu pecari), que estão na categoria "criticamente ameaçado", e o cateto (Tayassu tajacu), na categoria "vulnerável".

Percebemos então que a alteração ambiental causada pela construção de rodovias bem como pela sua utilização traz diversos impactos negativos para a fauna local, através da fragmentação e perda de hábitats, o que por sua vez influencia na morte de animais por atropelamentos que cruzam as rodovias em busca de abrigo, água e alimentos, além de locais e parceiros para reprodução, afetando principalmente espécies ameaçadas de extinção, podendo causar danos irreversíveis à natureza.

Nota-se também que os trechos das rodovias que estão próximos a áreas com vegetação exuberante e água em abundância foram os que apresentaram maiores índices de atropelamentos, por serem locais onde os animais circulam por maiores áreas, atravessando a rodovia em busca de condições de sobrevivência.

Sendo assim, conclui-se que, para conciliar a conservação da fauna e o desenvolvimento proporcionado pelas rodovias, é importante que haja um planejamento detalhado e cuidadoso ao construí-las, além da implantação e manutenção de medidas mitigadoras para que o desenvolvimento local seja possível, porém causando baixo impacto sobre a fauna e o meio ambiente como um todo.

\section{Considerações finais}

Algumas medidas preventivas podem ser implementadas para a redução dos atropelamentos nas rodovias, e os países da Europa estão investindo muito nisso. As estruturas mais comuns são redutores de velocidade, cercas de contenção, túneis e pontes como corredores. As quatro estruturas reduzem a mortalidade de animais causada por atropelamentos nas estradas.

As cercas de contenção são indicadas para os trechos onde o índice de atropelamentos é muito elevado. Estas estruturas carecem de uma manutenção constante, pois podem ser facilmente cortadas ou arrebentadas por caçadores e outras pessoas que eventualmente passem pela região. Para não causar o isolamento das populações, geralmente estão associadas a túneis e pontes de passagens, permitindo o deslocamento dos animais entre os dois lados da rodovia.

Os túneis e passagens subterrâneas são de diversos tamanhos e diâmetros, construídos abaixo da rodovia, permitindo a passagem dos animais sem o risco de sofrerem atropelamentos. Os de 1 metro a 1,5 metro de diâmetro são indicados para áreas que apresentam elevado número de atropelamentos de anfíbios e mamíferos de pequenos porte.

Porém, a instalação de redutores de velocidade, como os radares, é de baixo custo de implantação e manutenção, além de serem eficientes e não isolarem populações, permitindo a transposição dos animais entre os dois lados da rodovia. Outra medida de baixo custo é manter uma faixa de vegetação adjacente à rodovia sempre baixa, permitindo a visibilidade dos condutores dos veículos caso haja alguma animal atravessando a rodovia.

Outra medida que pode ser tomada, mas de menor resultado no número de atropelamentos de animais, é a instalação de placas sinalizando a presença de animais na região, alertando os motoristas para a redução da velocidade e maior atenção naquele trecho de rodovia.

De qualquer maneira, a implantação de medidas mitigadoras é eficaz na redução do número de atropelamentos de animais silvestres, porém necessita de estudos mais detalhados em cada trecho, para que apresentem os resultados esperados. Deve-se tomar o cuidado de escolher medidas que condizem com a realidade do local, evitando que os impactos negativos sejam maiores que os benefícios de sua implantação. 


\section{REFERÊNCIAS}

BAGATINI, T. Evolução dos índices de atropelamentos de vertebrados silvestres nas rodovias do entorno da Estação Ecológica Águas Emendadas, DF, Brasil, e a eficácia de medidas mitigadoras. Dissertação (Mestrado) Instituto de Ciências Biológicas da Universidade de Brasília, DF, 2006.

BANDEIRA, C; FLORIANO, E. P. Avaliação de impacto ambiental em rodovias. Santa Rosa, 2004. Caderno didático n. $8.16 \mathrm{p}$.

CASELlA, J.; CÁCERES, N. C.; GOULART, C. S.; PARANHOS FILHO, A. C. Uso de sensoriamento remoto e análise espacial na interpretação de atropelamentos de fauna entre Campo Grande e Aquidauana, MS. In: SIMPÓSIO DE GEOTECNOLOGIAS NO PANTANAL, 1, Campo Grande, Brasil, 11-15 novembro, Anais... Embrapa Informática Agropecuária/INPE, 2006, p.321-326,

CHEREM, J. J; KAMMERS, M; GHIZONI-JR, I. R; MARTINS, A. Mamíferos de grande e médio porte atropelados em rodovias do Estado de Santa Catarina, sul do Brasil. Revista Biotemas, v. 20, n. 3, p. 81-96, 2007.

CIOCHETE, G.; ABRA, F. Taxas de atropelamento de mamíferos de médio e grande porte e relações com a estrutura da paisagem nas Rodovias SP 225 e SP 310, São Paulo, SP. In: CONGRESSO DE ECOLOGIA DO BRASIL, 9, 13 a 17 de setembro, São Lourenço, MG. Anais... 2009

FISHER, W. A. Efeitos da rodovia BR-262 na mortalidade de vertebrados silvestres: síntese naturalística para a conservação da região do Pantanal, MS. 1997, 42 p. Dissertação (Mestrado) Universidade Federal do Mato Grosso do Sul, Campo Grande, MS, 1997.

FREITAS, C. H. Atropelamento de vertebrados nas rodovias MG-428 e SP-334 com análise dos fatores condicionantes e valoração econômica da fauna. 85 p. Tese (Doutorado), Instituto de Biociências da Universidade Estadual Paulista "Julio de Mesquita Filho", Campus de Rio Claro. 2009.

GUIMER-COSTA, F.; SPERBER, C. F. Atropelamentos de vertebrados na Floresta Nacional de Carajás, Pará, Brasil. Acta Amazônica, v.39, n.2, p.459 - 466, 2009.

HENGEMÜHLE, A.; CADEMARTORI, C. V. Levantamento de mortes de vertebrados silvestres devido a atropelamento em um trecho da estrada do mar (RS-389). Revista Biodiversidade Pampeana. PUCRS, Uruguaiana, v.6, n.2, p.4-10, dez, 2008.

LIMA, S. F.; OBARA, A. T. Levantamento de animais silvestres atropelados na BR-277 às margens do Parque Nacional do Iguaçu: subsídios ao programa multidisciplinar de proteção à fauna. 2004. Disponível em: <http://www.faunativa.com.br/downloads/impactos/ animais_atropelados_em_rodovias.pdf $>$. Acesso em: 21 maio 2011.
MELO, E. S.; SANTOS-FILHO, M. Efeitos da BR-070 na Província Serrana de Cáceres, Mato Grossa, sobre a comunidade de vertebrados silvestres. Revista Brasileira de Zoociências. v. 9, n.2, 185 - 192, dezembro, 2007.

MENEGUETTI, D. U. O.; MENEGUETTI, N. F. S. P.; TREVISAN, O. Georreferenciamento e reavaliação da mortalidade por atropelamento de animais silvestres na linha 200 entre os municípios de Ouro Preto do Oeste e Vale do Paraíso - RO. Revista científica da Faculdade de Educação e Meio Ambiente, v.1, n.1, p.58-64, maio-out, 2010.

MIKICH, S. B.; BÉRNILS, R. S. Livro Vermelho da Fauna Ameaçada no Estado do Paraná. 2004. Disponível em: $<$ http://www.pr.gov.br/iap>. Acessado em: 22 setembro 2011.

MOREIRA, F. G. A.; SILVA, S. S.; CUNHA, H. F. Impacto de atropelamento de animais silvestres na Rodovia GO-060, trecho Goiânia-Iporá. In: SEMINÁRIO DE INICIAÇÃO CINETÍFICA, 4. Universidade Estadual de Goiânia, Anais... 2006.

NOVELLI, R; TAKASE, E; CASTRO, V. Estudo das aves mortas por atropelamento em um trecho da rodovia BR471, entre os distritos da Quinta e Taim, Rio Grande do Sul, Brasil. Revista Brasileira de Zoologia. v.5, n.3, p.441 454, 1988.

PRADA, C. S. Atropelamento de vertebrados silvestres em uma região fragmentada do nordeste do estado de São Paulo: quantificação do impacto e analise de fatores envolvidos. 2004, 147 f. Dissertação (Mestrado) Universidade Federal de São Carlos, São Paulo, 2004.

PRADO, T. R; FERREIRA, A. A; GUIMARÃES, Z. F. S. Efeito da implantação de rodovias no cerrado brasileiro sobre a fauna de vertebrados. Acta Sci. Biol. Sci, Maringá, v. 28, n. 3, p. 237- 241, jul. /set. 2006.

ROSA, A. O.; MAUHS, J. Atropelamentos de animais silvestres na rodovia RS-040. Caderno de Pesquisa Sér. Bio. Santa Cruz do Sul, v. 16, n.1, p.35-42. jan/jun, 2004.

SCOSS, L. M. Impacto de estradas sobre mamíferos terrestres: o caso do Parque Estadual do Rio Doce, Minas Gerais. Dissertação (Mestrado), Universidade Federal de Viçosa, Minas Gerais, 2002.

SILVA, D. P.; BARBOSA, C. L.; GODOY, H. B. R. Mamíferos silvestres atropelados em trecho da BR-153 no estado de Tocantins. In: CONGRESSO BRASILEIRO DE ZOOTECNIA - INOVAÇÕES TECNOLÓGICAS E MERCADO CONSUMIDO, 21. Universidade Federal de Alagoas, Anais... 2011.

SILVA, G. J. T.; VIANNA, V. O. Levantamento de animais atropelados em trecho da Rodovia BR-376 nas proximidades no Parque Estadual de Vila Velha, Ponta Grossa, Paraná. Trabalho de conclusão de curso, Universidade Estadual de Ponta Grossa, Paraná, 2009. 
ZAÚ, A. S.; FREITAS, L. Efeitos de borda em um trecho de Floresta Atlântica, Parque Nacional da Tijuca, Rio de Janeiro, Brasil: Estrutura Física da vegetação arbóreoarbustiva. In: CONGRESSO DE ECOLOGIA DO BRASIL, 7, 23 a 28 de setembro, Caxambu, MG. Anais... 2007. 